\title{
An Instrument for Assessing the Organizational Benefits of IS Projects
}

Article in Decision Sciences · June 2007

DOI: 10.1111/j.1540-5915.1998.tb00878.x

CITATIONS

176

2 authors, including:

\section{Rajesh Mirani}

University of Baltimore

28 PUBLICATIONS 550 CITATIONS

SEE PROFILE
READS

748

Some of the authors of this publication are also working on these related projects:

Project (To be Decided) View project 


\title{
An instrument for assessing the organizational benefits of IS projects
}

\section{Rajesh Mirani; Albert L Lederer}

Decision Sciences; Fall 1998; 29, 4; ABI/INFORM Global pg. 803

\section{An Instrument for Assessing the Organizational Benefits of IS Projects}

\author{
Rajesh Mirani \\ Merrick School of Business, University of Baltimore, $1 / \mathrm{W}$. M. Roval Ave. - BC 404, Baltimore, \\ MD21201-5779,e-mail:rmirani@ubmail.ubalt.edu
}

\author{
Albert L. Lederer \\ 425C Business and Economics Building, Decision Sciences and Information Systems. Area, \\ School of Management, University of Kentucky, Lexington, KY 40506-0034, \\ e-mail:lederer@ukcc.ukj:edu
}

\begin{abstract}
This paper reports the development of an instrument to measure the organizational benefits of IS projects. The basis for this instrument was is published framework that suggests three categories of such benefits: strategic, informational, and transactional. In a cross-sectional study of 178 IS projects proposed and approved for development, this framework was operationalized and empirically tested using the measurement model of LISREL. The analysis culminated in the validation and refinement of the these categories. The final instrument offers items under three separate subdimensions of strategic benefits: competitive advantage, alignment, and customer relations. Informational benefits are similarly comprised of information access, information quality. and information flexibility. Finally, transactional benefits are also shown to be of three types: communications efficiency, systems development efficiency, and business efficiency. Implications of this multidimensional instrument for IS practitioners and researchers are discussed.
\end{abstract}

Subject Areas: Information Management, Management Information Systems, and Measurement.

\section{INTRODUCTION}

Information systems (IS) planning has long been a critical issue for both IS practitioners and researchers. Salient activities in the IS planning process include the determination of the organization's key information needs and opportunities, the identification of broad initiatives to respond to those needs and opportunities, and the justification and prioritization of specific IS projects based on their anticipated costs and benefits (McLean \& Soden, 1977; Willcocks \& Lester, 1991).

Much has been written about the costs of IS. There also exists a large body of literature on the specific benefits of IS, and some literature that suggests that the organizational benefits of IS can be grouped into broader categories or themes. 
However, there have been no systematic empirical attempts to operationalize these categories or themes. An empirically validated instrument that identifies the dimensions of the organizational benefits of IS by uncovering meaningful groups or categories would be of immense value to both researchers and practitioners for several reasons.

The instrument would provide a conceptual base for researchers to characterize proposed IS projects. It has been asserted that IS projects have heterogeneous themes in that different projects are expected to fulfill different management objectives (Weill, 1992). As an example, one type of system known as strategic IS is said to enhance organizational competitiveness (Ives \& Learmonth. 1984; Runge \& Earl, 1988; Clemons, 1991; Cash, McFarlan, McKinney. \& Applegate, 1992). However, there is controversy over whether strategic benefits are deliberately planned for (Powell, 1992). It is often argued that many information systems that are commonly touted as strategic systems started off as simple transaction processing systems (e.g., American Airlines' reservation system, Baxter's order processing system, etc.). An instrument to assess the organizational benefits of IS projects would allow researchers to identify proposed IS projects with various themes of benefits, and help preclude such controversies. It would also enable them to study the processes that lead to the anticipation of particular types of benefits, to identify the types of benefits that are realized more often, and to examine the reasons for the same.

In addition, such an instrument could help researchers generate better research designs and resolve conflicting findings. For instance, studies examining the link between IS investment and firm performance have reported contradictory results (Weill, 1992). This link has been found to be strong in some studies (Harris $\&$ Katz, 1991), weak in others (Lucas, 1975), and nonexistent in yet others (Turner, 1985). The instrument would enable researchers to distinguish between different types of IS investments based on their anticipated and realized benefits. Researchers would then be able to study these different types of IS projects in a heterogeneous manner. Such improved research designs would be more likely to yield consistent results and give researchers greater confidence in their findings.

For practitioners, the potential value of such an instrument is obvious. Senior executives could use it as one of several tools to asse's whether the expected benefits of a proposed project support overall business objectives, and to thereby approve or reject the project (Bacon, 1992). Alternatively, it could be employed in the post-implementation phase as an evaluation mechanism to assess whether anticipated benefits were realized. Critics have often claimed that the expected benefits of proposed information systems are not realized upon implementation (Loveman, 1988, 1991). It has also been suggested that senior executives are extremely dissatisfied with returns on corporate IT investments (Maglitta. 1993). The instrument would serve as an invaluable aid in demonstrating the benefits (or lack thereof) from IT investment in organizations. Senior management in individual organizations could also use it to assess the IS management's ability to meet its commitments and, thus, its credibility.

IS analysts would find the instrument useful for understanding and predicting the achievable benefits better and, thus, realizing them more often. Recurrent realization of predicted benefits would help generate positive attitudes among top 
management towards IS (Feeny, Edwards, \& Simpson, 1992). Moreover, this instrument would help analysts as well as functional area managers identify the kinds of projects that are more important to top management (Diromualdo, 1990). This information would guide IS managers in proposing new projects and recommending their priorities.

The study reported herein thus seeks to answer the following research questions: What are the major dimensions comprising the organizational benefits of IS projects? Can these dimensions be operationalized? The rest of this paper is organized as follows. First, the IS literature is searched for a strong theoretical framework that may serve as the basis for the development of an instrument to assess the organizational benefits of proposed IS projects. This section also includes a discussion of the organizational effectiveness literature as the basis for a strong caveat against exclusive reliance on individual theories or measurement instruments to capture complex constructs such as organizational IS benefits. After identifying and discussing several theories and frameworks, one is selected for this study and systematically operationalized. The adapted framework is then specified as a LISREL measurement model. This initial model is evaluated empirically using data collected from a cross section of IS practitioners across several industries. Taking the results of this evaluation as the starting point, the initial model is incrementally and iteratively modified to progressively improve its fit with the data while preserving its substantive sense. The resulting final model, a refined version of the initial model, represents a multidimensional instrument for assessing the organizational benefits of IS projects. This final revised model is revalidated empirically using additional data. The study concludes with a discussion of the implications of this instrument and its limitations.

\section{LITERATURE REVIEW AND RESEARCH FRAMEWORK}

The process of instrument development ideally involves the identification of appropriate theory as the basis for operationalization and empirical validation. Although one theory was indeed eventually adopted as the basis for the development of our instrument, it needs to be noted at the outset that this was by no means the "best" or most comprehensive theory. Indeed, it would be fallacious to assume that a single, best theory of the organizational benefits of IS projects even exists. The literature on IS effectiveness (of which organizational benefits can be considered a part or subset) abounds in theories that collectively focus on various levels (i.e., individual level, system level, organizational level), center around conflicting perspectives (users vs. IS), and are based on different models of effectiveness (e.g., strategic benefits, efficiency-oriented benefits, etc.). As a construct, IS effectiveness is so subjective and relative in nature that it would be unrealistic to expect to find a single best theory or framework. The literature on organizational effectiveness, a construct with inherent characteristics very similar to those of organizational IS benefits, offers some clues as to why this may be the case. For example, Cameron (1986) asserted that organizational effectiveness as a theoretical construct is a moving target whose nature and definition change as various metaphorical organizational models fall in and out of favor with researchers. The point is also made that a comprehensive, consensual set of indicators for the measurement 
of effectiveness may be impossible to obtain because the underlying thenretical criteria are based on the values and preferences of individuals and constituent groups, which are interpretations of their own subjective models of reality, and which may conflict with each other (Cameron \& Whetten, 1983). Further, different models of effectiveness may be useful for research in different circumstances. depending on the problem and context. Elsewhere, it has been noted by Zammuto (1984) that numerous "multiple constituency" models of organizations consider organizational effectiveness criteria to be a derivation of the outcome preferences of the individual constituencies. The multiple constituency perspective for effectiveness measurement has also been endorsed by others (Hall, 1996).

There are two major implications of the above discussion for IS effectiveness research. One is that different constituencies have different perspectives, all of which may be equally important. For instance, users and IS professionals may differ on the nature of benefits anticipated from any given IS development project. From the point of view of success measurement, it is important to understand exactly what both the users and IS professionals expect from the project so that success can be measured relative to their expectations. The other major lesson for IS effectiveness research (and for this instrument development endeavor) is that no single theory or measuring instrument should (or can) be expected to capture all aspects and dimensions of IS benefits in every circumstance. Rather, researchers interested in acquiring a complete understanding of IS effectiveness/benefits in a given context need to make use of multiple tools that collectively address both user and IS professionals' perspectives, focus on individual, system, as well as organizational levels of effectiveness, and use different frameworks as underlying theoretical bases. Thus, although our study describes the development of an instrument focusing on the measurement of IS benefits at the organizational level, it should be noted that the instrument resulting from this effort should not be considered as the one and only tool necessary to assess such benefits in all contexts. Rather, its applicability should be dictated by circumstance and context, and by the objectives of any study for which it is considered. In addition, whenever possible, this instrument should be considered as part of a portfolio of tools (e.g., other measuring instruments for measuring similar and related constructs) rather than a comprehensive, superior, stand-alone tool. The combined use of multiple tools, as opposed to any single tool, is more likely to provide a truer depiction of a given contexı due to the reasons discussed above. For example, our instrument, which focuses on organizational level benefits, can be used in conjunction with the user satisfaction instrument by Ives, Olson, and Baroudi (1983), which focuses on individual-level benefits. As noted by Klein, Dansereau, and Hall (1994) and others (Rousseau, 1985; Ostroff, 1993), it is acceptable to summarize and aggregate individual-level data to the organizational level as long as there is some empirical evidence of organizational homogeneity.

Thompson (1967) offered additional insights into the issue of effectiveness assessment. He stated that the assessment of organizational effectiveness involves two independent variables: (a) standards of desirability, and (b) understanding of cause/effect relations. Standards of desirability relate to coveted organizational goals, which may be clearly known or ambiguous. Understanding of cause/effect relations pertains to the knowledge of associations between actions and their 
outcomes, which may be complete or incomplete. Combining these two dimensions results in four possible extreme scenarios that may be summarized as follows: (i) crystallized-complete, (ii) crystallized-incomplete, (iii) ambiguous-complete, and (iv) ambiguous-incomplete.

In the first scenario, in which goals are clear and cause/effect understanding is complete, maximization or "efficiency" is the appropriate approach to organizational assessment, since it is possible to test whether the desired goals were achieved with the minimum possible consumption of resources. In the second scenario, in which cause/effect understanding is incomplete, the efficiency test becomes inappropriate, and the proper assessment approach would be a less stringent "instrumental" test to simply check whether the desired end goals were reached. In the third and fourth scenarios, in which standards of desirability (goals) are ambiguous, neither efficiency tests nor instrumental tests are applicable, and assessment has to fall back on "social tests" using various reference groups.

Thompson's (1967) classic work has profound implications for the assessment of organizational IS benefits. As impacts of organizational IS projects are said to be often indirect, subtle, complex, multiple, and perceptible only over a long time period (Dos Santos, 1991), it may be argued that the standards of desirability vis-a-vis IS benefits are often ambiguous, and the knowledge of cause and effect in this context often incomplete. This is particularly true when cost reduction or efficiency enhancement is not the primary motivation behind new applications, as is increasingly the case these days (see discussion on strategic benefits below). Assessment of the organizational IS benefits, therefore, is a complex endeavor that requires a greater use of instrumental and social tests as opposed to efficiency tests. The logic of this argument is congruent with the fact that much of the IS effectiveness literature has focused on the development of instrumental tests centered on specific reference groups. In particular, the various efforts to develop user satisfaction instruments (as discussed below) are noteworthy.

The remainder of this section applies the lessons learned from the organizational effectiveness literature in the form of a discussion of various theories that provide diverse perspectives on the organizational benefits of IS projects. This discussion attempts to mirror the temporal progression of theories. It is also interesting that this temporal sequence begins with a theory of IS benefits centered around simple, efficiency-oriented, organizational-level considerations and gradually evolves to complex frameworks that account for multiple constituencies and several different levels of benefits. The section concludes with a justification for the theory selected as the basis for the development of our instrument.

\section{Organizational Benefits of IS-Diverse Perspectives}

One of the earliest theories of IS benefits was provided by King and Schrems (1978). Their discussion of IS benefits was oriented along efficiency considerations and focused at the level of the organization as a whole. They classified IS benefits into the following categories: benefits from contributions of calculating and printing tasks, benefits from contributions to record-keeping tasks, benefits from contributions to record-searching tasks, benefits from contributions to system restructuring capability, benefits from contributions of analysis and simulation 
capability, and benefits from contributions to process and resource control. Not surprisingly, their categories reflected the predominant transactional uses of IS at the time. The authors also briefly mentioned that some benefits could be intangible or difficult to quantify.

The notion that information systems could create strategic benefits or competitive advantage for the organization was conceptualized and popularized a few years later. Strategic information systems were supposed to make a company more flexible, responsive, and adaptive. Many research studies focused on the identification of strategic benefits and how to plan for and achieve them via information technology (IT) (Parsons, 1983; Ives \& Learmonth, 1984; Cash \& Konsynski, 1985; Porter \& Millar, 1985; Bakos \& Treacy, 1986). For example, Parsons asserted that IT could be used by a firm to implement its existing competitive strategy, to affect its key competitive forces such as buyers, suppliers and rivals, as well as to change the products, markets, or production economics of an entire industry. This entire line of research also focused on benefits at the overall organizational level, although the nature of IS benefits in these studies were very different from those identified by King and Schrems (1978).

Following the recognition of the wider range of potential benefits of IS, Weill (1992) offered a more comprehensive framework of benefits at the level of the organization as a whole. In this framework, which was derived and extended from an earlier published work by Turner and Lucas (1985), all IT investments were classified based on the organizational objectives they would help achieve. Three types of objectives were identified as strategic, informational, and transactional. Strategic IT changes an organization's product or the way in which the organization competes. Informational IT provides the information and communication infrastructure of the organization. Transactional IT supports operational management and helps cuts costs. It is possible for a single IS to have objectives of all three kinds. Weill used the proposed framework in empirical research studies (Weill \& Olson, 1989; Weill). Although the three-way classification itself was never tested for empirical validation, an earlier, similar framework from Gorry and Scott Morton (1971) did receive some support in a validation study (Kirs, Sanders, Cerveny, \& Robey, 1989).

In a largely independent line of research that evolved during a period roughly concurrent with the strategic benefits school of thought (but with slightly prior origins), numerous studies focused on the examination of surrogates for IS effectiveness. Almost all these studies explored IS benefits at the individual and system levels, as opposed to the strategic benefits literature, which focused mostly at the organizational level. At the user level, such studies mainly consisted of efforts to develop measuring instruments for assessing user information satisfaction (Jenkins \& Ricketts, 1979; Bailey \& Pearson, 1983; Ives et al., 1983; Raymond, 1985; Doll \& Torkzadeh, 1988). At the system level, there were efforts to explore system usage as a surrogate of IS effectiveness (Barti \& Huff, 1985; Srinivasan, 1985). Some of these studies were criticized for a lack of theoretical basis (Kim, 1989; Melone, 1990; Subramanian \& Nilakanta, 1994). However, this line of research provided uniquely important perspectives in the quest to understand a fuzzy construct-IS effectiveness-for reasons discussed above. 
Kauffman and Weill (1989) conducted an extensive review of the literature on IT benefits and their measures, and sounded a note of caution for researchers. Their assertion was that researchers should be careful in how they select the "unit of analysis" and "locus of value" in generating research designs. Unit of analysis is the level at which data are gathered and analyzed, examples of which are the individual level and the firm level. Locus of value represents the nature of IT value measured, examples of which are user satisfaction and firm performance. They also stated that in practice it was not always feasible or even desirable for the unit of analysis to be determined from the locus of value.

DeLone and McLean (1992) synthesized a six-dimensional taxonomy of IS success based on a review of 180 published conceptual and empirical studies. The dimensions were: system quality, information quality, use, user satisfaction, individual impact, and organizational impact. In their taxonomy, dimensions such as use, user satisfaction, and individual impact represent intermediate stages in the path leading to the ultimate success dimension: organizational benefits of IS. This taxonomy addresses IS benefits at all three levels--individual, system, and organizational - and is congruent with many of the lessons learned from the organizational effectiveness literature. DeLone and McLean did not elaborate on the nature of benefits under the "organizational impact" category, the focus of our research.

Farbey, Land, and Targett (1995) conducted an interesting analysis by relating IS benefits to the types of IS applications. They identified eight categories of IS applications which they termed an "8-rung ladder." In this metaphorical ladder, application categories that constituted the higher rungs were said to be associated with high complexity in evaluating their potential benefits. Higher rungs were also associated with greater potential gains as well as increased risk and uncertainty. Conversely, application categories that formed the lower rungs of the ladder were easily evaluated in terms of their potential benefits, and were associated with fewer potential benefits as well as reduced risk and uncertainty. Table 1 summarizes the major theoretical contributions to the published literature on IS benefits.

\section{Selected Framework}

Turner and Lucas's (1985) theory as extended by Weill (1992) was adopted as the research framework for our study. Several considerations influenced this choice. The three categories in this framework (strategic, informational, and transactional) provide an appropriate basis for the consideration of organizational benefits (as opposed to individual- or system-level benefits) as the locus of value. They are also well defined, easy to understand, and distinct from each other. In addition, the framework itself has been adopted as the basis for other empirical studies. All these factors contributed to its selection. The remainder of this paper describes how this framework was operationalized, empirically tested, and iteratively refined using data collected from IS professionals, culminating with a validated instrument that captured the many dimensions and subdimensions of the organizational benefits of IS projects. 
Table 1: Major contributions to published literature on IS/IT benefits.

\begin{tabular}{ll}
\hline Author(s) & \multicolumn{1}{c}{ Conclusions } \\
\hline King \& Schrems (1978) & Classified benefits of information systems into six \\
& categories: (a) contributions of calculating and printing \\
& tasks, (b) contributions to record-keeping tasks, (c) \\
& contributions to record-searching tasks, (d) contributions \\
& to system restructuring capability, (e) contributions of \\
& analysis and simulation capability, and (f) contributions to \\
& process and resource control.
\end{tabular}

Jenkins \& Ricketts (1979) Developed an instrument to measure user satisfaction with management information systems.

Bailey \& Pearson (1983) Developed an instrument to measure computer user satisfaction.

Ives et al. (1983)

Further developed and refined Bailey and Pearson's (1983) user satisfaction instrument.

Parsons (1983) Suggested that IT could be used by a firm to implement existing competitive strategy, to affect key competitive forces, and to change the products, markets, or production economics of the industry.

Porter \& Millar (1985) Suggested that information technology affects competition in three ways: it alters industry structures, supports cost and differentiation strategies, and spawns new businesses.

Raymond (1985)

Srinivasan (1985)

Developed an instrument to measure user satisfaction in small businesses.

Discussed the relevance of system usage and other measures as surrogates for system effectiveness.

Doll \& Torkzadeh (1988) Developed an instrument to measure end-user computing satisfaction.

Kauffman \& Weill (1989) Offered a framework for research on the performance effects of IT investments, and suggested that researchers carefully select the "unit of analysis" and "locus of value" in generating research designs.

Weill \& Olson (1989)

Concluded from analysis of six mini case studies in five different industries that the effectiveness with which IT investment is converted to useful output is affected by implementation processes, organizational culture, and management skills.

Dos Santos (1991)

Suggested that new IT investments may yield indirect benefits as well as direct benefits, where indirect benefits would accrue from future projects that used the new technology. 
Table 1: (continued) Major contributions to published literature on IS/IT benefits.

DeLone \& McLean (1992) Synthesized the published literature and proposed a taxonomy of IS success consisting of six dimensions: system quality, information quality, use, user satisfaction, individual impact, and organizational impact. Dimensions such as use, user satisfaction, and individual impact were said to represent intermediate stages in the path leading to the organizational benefits of IS.

Weill (1992)

Classified IT investments based on three types of organizational objectives: strategic, informational, and transactional. Suggested that it was possible for a single IS to have objectives of all three kinds. Used a similar framework in another empirical study (Weill \& Olson, 1989).

Farbey et al. (1995)

Identified "8-rung ladder" of IS applications. Higher rungs were associated with high complexity in evaluating potential benefits, greater potential gains, increased risk and uncertainty.

\section{RESEARCH METHODOLOGY}

The research framework adopted for this study was first used as the basis for a literature survey and the generation of a preliminary instrument. This instrument was pre-tested, modified, and used to capture data in a cross-sectional survey of IS practitioners. Data gathered in this survey were used to further refine the instrument in iterative steps. The "measurement model" of LISREL was employed in these iterations. The following paragraphs describe these processes in detail.

\section{Operationalization}

The three categories of IS benefits in the adopted framework were operationalized by searching the IS literature for references to specific IS benefits that could "populate" (i.e., serve as indicators or observable variables for) the strategic, informational, a nd transactional categories. To this end, a list of several specific benefits, with on: or mrere references to each, was first methodically compiled. Care was taken to discard redundancies and to ensure that the specific benefits retained were mutually exclusive. The resulting list of specific benefits was pilot tested with IS practitioners. Participants in the pilot test were asked to first completely fill out a questionnaire (described in detail in the Data Collection section) and then to provide an open-ended critique of its contents, readability, and format, as well as to identify any other potential problems, particularly with the list of benefits. After some minor changes, this procedure culminated with the identification of 33 specific benefits (Table 2).

Next, each of the 33 specific benefits was assigned to one of the three categories. Each specific benefit thus became one of several indicators for assessing the presence of a particular category of benefits. To reduce the potential bias stemming 
Table 2: Potential benefits of IS projects.

Benefit

(Item

Number) The Proposed Project Will...

Supporting Literature

1. Save money by reducing the work force.

Orli \& Tom, 1987; Parker \& Benson, 1987; Rivard \& Kaiser, 1989;

Sullivan-Trainor, 1990-91

2. Save money by avoiding the need to

Smith, 1983 increase the work force.

3. Save money by reducing travel costs.

Smith, 1983

4. Save money by reducing

Smith, 1983 communication costs.

5. Save money by reducing system

Smith, 1983; Vaid-Raizada, 1983 modification or enhancement costs.

6. Save money by reducing hardware use.

Orli \& Tom, 1987

7. Change the way the organization conducts business.

Parker \& Benson, 1987; Sullivan-

Trainor, 1990-91

8. Enhance competitiveness or create strategic advantage.

Janulaitis, 1984; Lay, 1985;

McGugan, 1987; Parker \& Benson, 1987; Sullivan-Trainor, 1989;

Anonymous, 1990; Sullivan-Trainor, 1990-91

9. Enable the organization to catch up with competitors.

Parker \& Benson, 1987

10. Align well with stated organizational goals.

11. Facilitate organizational adherence to governmental regulations.

12. Help establish useful linkages with other organizations.

13. Improve management information for strategic planning.

Parker \& Benson, 1987

(Added during pilot.)

Parker \& Benson, 1987

King \& Schrems, 1978; Parker \& Benson, 1987

14. Enhance the credibility and prestige of the organization.

Orli \& Tom, 1987

15. Allow other applications to be

Smith, 1983 developed faster.

16. Allow previously infeasible applications to be implemented.

Orli \& Tom, 1987; Sullivan-Trainor, 1990-91 
Table 2: (continued) Potential benefits of IS projects.

Benefit

(Item

Number) The Proposed Project Will...

Supporting Literature

17. Enable faster retrieval or delivery of information or reports.

18. Present information in a more concise manner or better format.

19. Increase the flexibility of information requests.

20. Provide the ability to perform maintenance faster.

21. Enable easier access to information.

22. Improve the accuracy or reliability of information.

23. Increase the volume of information output.

24. Improve customer relations.

25. Provide new products or services to customers.

26. Provide better products or services to customers.

27. Improve information for management control.

28. Improve information for operational control.

29. Speed up transactions or shorten product cycles.

30. Increase return on financial assets.

31. Enhance employee productivity or business efficiency.

32. Provide greater data or software security.

33. Enable the organization to respond more quickly to change.
Rivard \& Kaiser, 1989; SullivanTrainor, 1989

Rivard \& Kaiser, 1989

King \& Schrems, 1978; Orli \& Tom, 1987

(Added during pilot.)

Orli \& Tom, 1987; Rivard \& Kaiser, 1989

King \& Schrems, 1978; Vaid-

Raizada, 1983; Orli \& Tom, 1987;

Rivard \& Kaiser, 1989

Rivard \& Kaiser, 1989; Sullivan-

Trainor, 1989

Orli \& Tom, 1987; Rivard \& Kaiser, 1989

Sullivan-Trainor, 1989

Parker \& Benson, 1987; SullivanTrainor, 1989; Anonymous, 1990

King \& Schrems, 1978; Orli \& Tom, 1987; Parker \& Benson, 1987

Parker \& Benson, 1987

Anonymous, 1990; Orli \& Tom, 1987; Parker \& Benson, 1987

(Added during pilot.)

King \& Schrems, 1978; McGugan, 1987; Rivard \& Kaiser, 1989; Smith, 1983; Sullivan-Trainor, 1989; Sullivan-Trainor, 1990-91

Vaid-Raizada, 1983

(Added during pilot.) 
from the subjective nature of this process, two expert raters independently classified each benefit. The two raters initially classified 29 of the 33 benefits in an identical manner. This translated to an initial agreement rate of $87.8 \%$, and detailed analysis revealed a Cohen's kappa coefficient of .813. Cohen's kappa coefficient is an indicator of the proportion of agreement between two raters of nominal data (as in classification or categorization tasks) that accounts for the probabilities of chance agreements (Cohen, 1960). This coefficient is appropriate for our context because its underlying theory recognizes that raters often distribute their judgments differently over categories. In other words, it does not require the assumption of equal distribution of ratings across various categories. Although a more sophisticated indicator called "weighted kappa" also exists, it is more suited to contexts in which disagreements have degrees of severity, which would be the case if the various categories represented a continuum of some sort (Cohen, 1968).

The four benefits that were classified differently were: (i) change the way the organization conducts business, (ii) facilitate organizational adherence to governmental regulations, (iii) provide greater data or software security, and (iv) enable the organization to respond more quickly to change. After some discussion the raters also agreed on the classification of these four benefits. In the end, the strategic, informational, and transactional categories consisted of 10,9 , and 14 indicators, respectively. These indicators under each category are depicted in Table 3.

\section{Data Collection}

A cross-sectional survey of IS practitioners was used for data collection. A questionnaire was developed for this purpose. In the instructions at the beginning of the questionnaire, respondents were asked to recall the most recently approved or disapproved large project proposal for which they participated in a formal benefits estimation process. They were asked to respond to the questions in the context of this one recent project. Major parts of the questionnaire included:

- A set of questions about the project. Respondents identified the proposer, type of application, functional area of application, benefits analysts, approver, and budget for the project.

- A list of 33 potential benefits of IS. Respondents identified the importance of each anticipated benefit relative to the other anticipated benefits of the proposed project on a 1 to 7 scale $(1=$ not a benefit, $7=$ very important $)$.

- Demographic questions about the organization and respondent.

Respondents were permitted to augment the responses to many of the questions. For example, they could add an anticipated benefit if it was not already identified in the questionnaire.

The questionnaire was mailed to 936 randomly selected members of a nationwide association of over 3500 information systems managers and analysts. After a reminder mailing to nonrespondents, a total of 200 valid responses were received. Because 33 questionnaires were returned with incorrect addresses, the response rate was $22 \%$.

All the respondents participated in or supervised the identification of benefits for the project they reported and, hence, were knowledgeable about the questions 
Table 3: Benefits of IS projects: Hypothesized (initial) dimensions and indicators (items).

\begin{tabular}{lc}
\hline & Benefit \\
Indicator & (Item Number) \\
in Table 2
\end{tabular}

\section{Strategic Dimension}

Change the way the organization conducts business.

Enhance competitiveness or create strategic advantage. 8

Enable the organization to catch up with competitors. $\quad 9$

$\begin{array}{ll}\text { Align well with stated organizational goals. } & 10\end{array}$

Help establish useful linkages with other organizations. 12

Enhance the credibility and prestige of the organization. 14

Improve customer relations. $\quad 24$

Provide new products or services to customers. 25

Provide better products or services to customers. 26

Enable the organization to respond more quickly to change. 33

\section{Informational Dimension}

Improve management information for strategic planning. 13

$\begin{array}{ll}\text { Enable faster retrieval or delivery of information or reports. } & 17\end{array}$

$\begin{array}{ll}\text { Present information in a more concise manner or better format. } & 18\end{array}$

$\begin{array}{ll}\text { Increase the flexibility of information requests. } & 19\end{array}$

Enable easier access to information. 21

Improve the accuracy or reliability of information. 22

Increase the volume of information output. 23

Improve information for management control. 27

Improve information for operational control. 28

\section{Transactional Dimension}

Save money by reducing the work force. 1

Save money by avoiding the need to increase the work force. 2

Save money by reducing travel costs. 3

Save money by reducing communication costs. 4

Save money by reducing system modification or

enhancement costs. 5

Save money by reducing hardware use. $\quad 6$

Facilitate organizational adherence to governmental regulations. 11

Allow other applications to be developed faster. 15

Allow previously infeasible applications to be implemented. 16

Provide the ability to perform maintenance faster. 20

Speed up transactions or shorten product cycles. 29

Increase return on financial assets. $\quad 30$

Enhance employee productivity or business efficiency. 31

$\begin{array}{ll}\text { Provide greater data or software security. } & 32\end{array}$ 
they were asked to answer. However, it should be noted that their responses represent the perceptions of information systems managers and analysts, and these could differ considerably from those of users and others.

\section{Respondent Characteristics}

Respondents were generally highly experienced and educated. They had worked in information systems for an average of 20 years with the past 12 at their current employer. Approximately 24 employees reported to each respondent with a range of 0 to 480 . Over $86 \%$ had a four-year degree and about half had attended at least some graduate school. About one-third of their firms were in manufacturing, while insurance and government were the second and third most prominent employers. Their firms' IS departments had an average of 785 employees. Annual IS budgets averaged $\$ 52$ million with a range of $\$ 60,000$ to $\$ 2$ billion.

One hundred ninety of the 200 respondents answered a question as to whether or not their proposed project was ultimately approved. The number of projects approved was $178(94 \%)$. Thus, only 12 of the 190 projects progressed through the entire cost/benefit decision analysis without ultimately receiving management approval. One possible reason for the high proportion of approved projects is that clearly nonjustifiable projects are rarely presented for approval. For the sake of homogeneity of data, the subsequent analysis uses these 178 projects only.

Table 4 shows some characteristics of these projects, namely the proposer of the project, its application type, the functional areas affected by it, the participants in its benefits analysis, and its final approver. Respondents could check more than one alternative for the proposer, application, functional area, and participants questions. Hence, the percentages in those portions of the table sum to more than $100 \%$. (Their doing so suggests the collaborative nature of benefits analysis and the overlapping nature of IS project application types and functional areas.)

The most frequent proposers of projects were user departments, who suggested $61 \%$ of all projects; despite the current interest in planning, strategic planning groups proposed a much smaller percentage (17\%). The most common applications were transaction processing systems $(54 \%)$ and management information systems $(51 \%)$. Although the leading functional area was production (33\%), accounting ( $24 \%$ ) and finance $(22 \%)$ projects also had a share. Both IS management $(81 \%)$ and user management $(78 \%)$ participated more frequently in the benefits analysis than did their subordinate user representatives and analyst/ programmers. However, the $\mathrm{CEO}$ was required to give final approval in nearly half $(45 \%)$ the projects. Perhaps this was because the average budget of the projects was $\$ 3.8$ million with a range of $\$ 4,000$ to $\$ 100,000,000$.

The projects in the sample represent a wide assortment. The sample represents a variety of industries and sizes. Moreover, no two respondents came from the same firm. These facts contribute to the generalizability of the results of this study. As a further test of generalizability, the group of 81 who responded to the first mailing were statistically compared (using $t$-tests) with the group of 97 who responded to reminder mailings, in terms of organizational, individual, and IS project demographics (Table 5). These comparisons revealed no significant differences and, thus, vastly diminished the possibility of the presence of nonresponse biases. 
Table 4: Project characteristics.

\begin{tabular}{|c|c|c|}
\hline & Number & Percent \\
\hline \multicolumn{3}{|l|}{ Proposers } \\
\hline User department & 108 & 61 \\
\hline Information systems department & 78 & 44 \\
\hline Top management & 63 & 35 \\
\hline Strategic planning group & 32 & 17 \\
\hline Other individual employee & 4 & 2 \\
\hline Other & 11 & 6 \\
\hline \multicolumn{3}{|l|}{ Application } \\
\hline Transaction processing system & 96 & 54 \\
\hline Management information system & 90 & 51 \\
\hline Decision support system & 44 & 24 \\
\hline Office automation & 28 & 16 \\
\hline Executive information system & 16 & 9 \\
\hline Expert system & 6 & 3 \\
\hline Other & 30 & 17 \\
\hline \multicolumn{3}{|l|}{ Functional Area } \\
\hline Production & 58 & 33 \\
\hline Accounting & 42 & 24 \\
\hline Finance & 38 & 22 \\
\hline Marketing & 31 & 17 \\
\hline Human resources & 19 & 11 \\
\hline Research \& development & 12 & 7 \\
\hline Other & 57 & 32 \\
\hline \multicolumn{3}{|l|}{ Participants in Benefits Analysis } \\
\hline IS department management & 145 & 81 \\
\hline User management & 139 & 78 \\
\hline User representatives & 108 & 61 \\
\hline IS analyst/programmers & 94 & 52 \\
\hline Other & 24 & 13 \\
\hline \multicolumn{3}{|l|}{ Final Project Approval } \\
\hline Chief executive officer/president & 73 & 45 \\
\hline Steering committee & 27 & 17 \\
\hline User vice president & 16 & 9 \\
\hline Financial vice president/controller & 11 & 7 \\
\hline Chief information officer & 11 & 7 \\
\hline Other vice president & 2 & 1 \\
\hline Other & 23 & 14 \\
\hline
\end{tabular}

Reproduced with permission of the copyright owner. Further reproduction prohibited without permission. 
Table 5: Nonresponse bias analysis.

\begin{tabular}{lcrrr}
\hline & $\begin{array}{c}\text { 1st Mailing } \\
\text { Respondents } \\
\text { Chan }\end{array}$ & $\begin{array}{c}\text { Reminder Mailing } \\
\text { Respondents' } \\
\text { Mean }\end{array}$ & t-value & $p$ \\
\hline $\begin{array}{l}\text { Organizational } \\
\text { Annual sales (\$ billion) }\end{array}$ & $2.97^{45}$ & $2.95^{47}$ & 0.01 & .99 \\
Total number of employees & $6573.69^{78}$ & $9187.88^{88}$ & -0.88 & .38 \\
$\begin{array}{l}\text { Individual Respondent } \\
\text { Years of experience in IS }\end{array}$ & $18.12^{78}$ & $20.34^{86}$ & -1.80 & .07 \\
Years with current employer & $10.95^{78}$ & $12.87^{86}$ & -1.57 & .11 \\
IS Project Reported & & & & \\
Approved budget (\$ million) & $2.53^{60}$ & $3.13^{51}$ & -0.27 & .78 \\
\hline
\end{tabular}

Note: Numbers in superscripts indicate sample sizes of respective groups.

\section{The Measurement Model of LISREL}

The first step in data analysis was to assess whether the strategic, informational, and transactional categories were indeed three distinct dimensions representing organizational benefits of IS projects. If this were a purely exploratory research with no a priori hypotheses regarding the underlying structures of the latent constructs, a simple principal components analysis (PCA) would have sufficed in acquiring an initial understanding of these structures. Following this, confirmatory studies with different data sets would be used to gradually refine the initial models, and these would ultimately result in a more consensual understanding of the precise structures of these constructs.

In this study, however, the latent structure of the constructs (i.e., the dimensions) had been hypothesized a priori and, therefore, something stronger than an exploratory statistical tool was needed to test and/or refine the hypothesized structures. The measurement model of LISREL VI was employed for this purpose (Jöreskog \& Sörbom, 1986). The LISREL measurement model is used to statistically represent the hypothesized structure and to assess how well the observed variables (indicators) reflect unobserved or latent variables (the dimensions). In other words, it provides a confirmatory assessment of convergent validity and discriminant validity (Campbell \& Fiske, 1959).

This verification process of a construct's structure hypothesized a priori, theoretically is referred to as confirmatory factor analysis (CFA). In practice. however, the process rarely turns out to be purely confirmatory because the initially specified measurement models almost never provide a totally acceptable fit with the data. The usual solution to this lack of an initial perfect fit involves respecifying the initial model based on the results of the analysis and reestimating the resulting new model using the same data in successive iterations. This procedure is, thus, not purely confirmatory in nature. Rather, it lies somewhere along a continuum between exploratory factor analysis (EFA) and confirmatory factor analysis (CFA), and a more appropriate term for it is restricted analysis (Anderson \& Gerbing, 
1988). This study employed such a restricted analysis in order to uncover the dimensions or categories of organizational IS benefits.

To begin this analysis, the hypothesized structures of the strategic, informational, and transactional dimensions were first represented separately as three LISREL measurement models. These three models are depicted in Figure 1. Each model represents one of the three latent dimensions and its respective observed indicators. Similar models have been employed in past research (Venkatraman \& Ramanujam, 1987; Raghunathan \& Raghunathan, 1994). In keeping with the notations of structural equation modeling, latent variables are drawn as ellipses and observable indicators as squares. The three models were estimated using the maximum likelihood (ML) method.

It should be emphasized here that the three hypothesized dimensions were intentionally represented and analyzed separately as three LISREL measurement models instead of being included and analyzed together in a single measurement model. This was done because the adopted framework clearly stipulated the presence of three dimensions for IS benefits, and because our objective was not to generate a totally new theory founded solely on empirical criteria. In other words, our belief that substantive and theoretical issues must take precedence over empirical concerns resulted in the decision to separately analyze the three models. As the next section demonstrates, the three dimensions were examined for, and found to possess, discriminant validity.

\section{RESULTS}

\section{Discriminant Validity of the Initial Models}

Discriminant validity is the degree to which a dimension in a theoretical system differs from other dimensions in the same theoretical system. Discriminant validity for two dimensions can be assessed by constraining the estimated correlation parameter $\left(\phi_{i j}\right)$ between them to 1.0 and then performing a chi-square difference test on the values obtained for the constrained and unconstrained models (Jöreskog, 1971). A significantly lower chi-square value for the unconstrained model indicates that the traits are not perfectly correlated and that discriminant validity is achieved (Bagozzi \& Phillips, 1982). More precisely, a chi-square difference value (chi-square ${ }_{d}$ ) with an associated $p<.05$ provides evidence of discriminant validity (Jöreskog). When there are more than two dimensions, this test should be performed separately for each pair of dimensions. This is done so that any specific pairs of dimensions that do not show significant differences between their constrained and unconstrained models can be isolated from other pairs that do show significant differences.

As the informational, strategic, and transactional dimensions form three pairs in all, three pairwise analyses were conducted to assess overall discriminant validity. Each such analysis compared the constrained and unconstrained model for a given pair of dimensions. For the strategic-informational pair, the difference between the chi-square values for the constrained and unconstrained models was 248.83. The differences for the strategic-transactional and the informationaltransactional pairs were 51.85 and 71.14 , respectively. All three analyses yielded 
Figure 1: The initial strategic, informational, and transactional models.
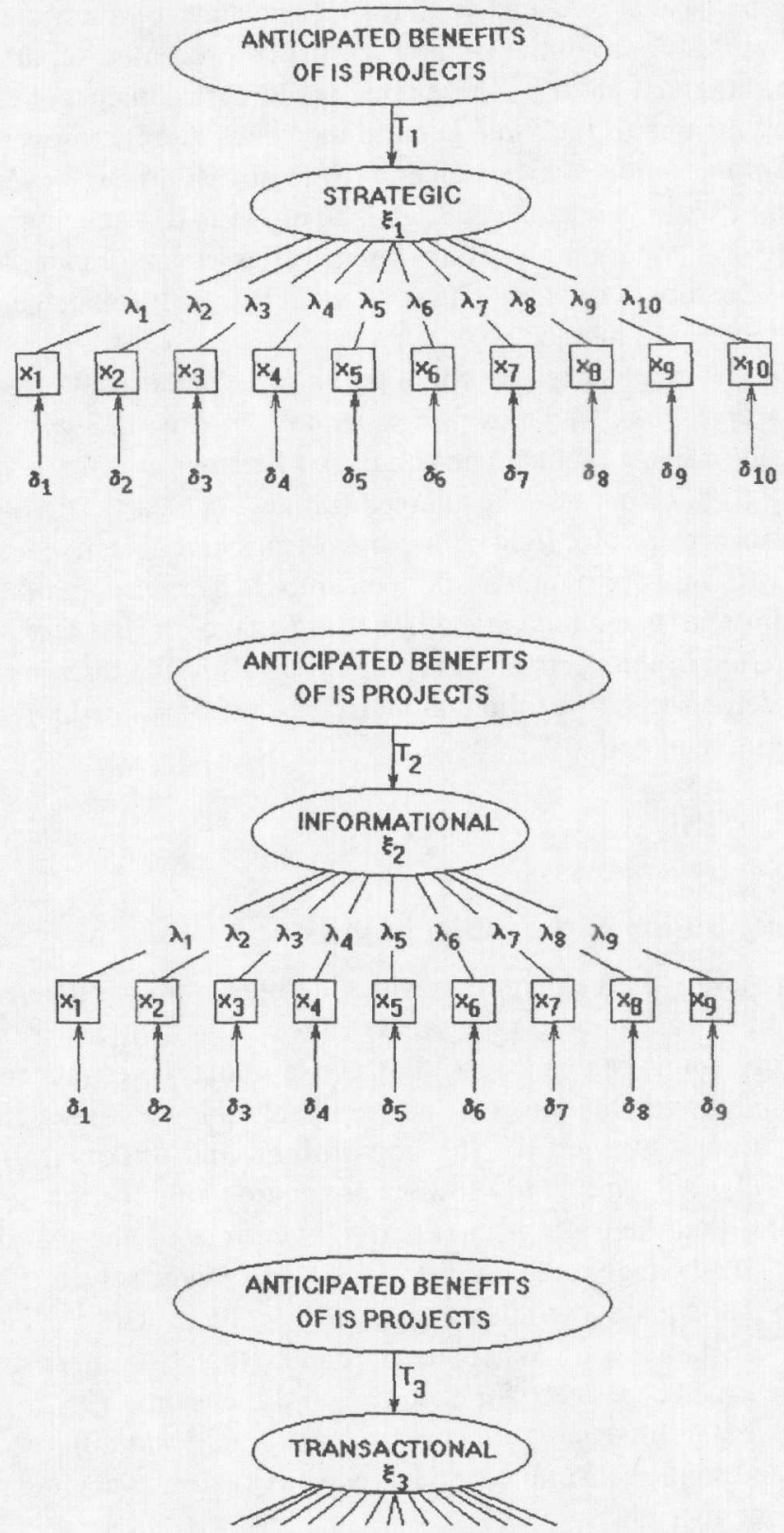

$\lambda_{1} \lambda_{2} \lambda_{3} \lambda_{4} \lambda_{5} \lambda_{6} \lambda_{7} \lambda_{8} \lambda_{9} \lambda_{10} \lambda_{11} \lambda_{12} \lambda_{13} \lambda_{14}$

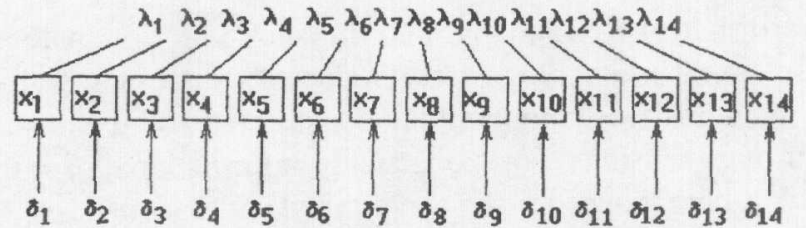

Reproduced with permission of the copyright owner. Further reproduction prohibited without permission. 
significantly lower chi-square values for the respective unconstrained models as compared to the constrained models $(p \leq .001)$. This was strong evidence of discriminant validity. Table 6 provides the full correlation matrix for the 33 indicators, and Table 7 summarizes the statistics described above.

\section{Unidimensionality and Convergent Validity of the Initial Models}

After ensuring that the three dimensions were distinctly different from each other, our next objective was to individually examine each one for unidimensionality or convergent validity. For each of the three models depicted in Figure 1, convergent validity was assessed with the help of four criteria (Jöreskog \& Sörbom, 1986). One criterion used was the chi-square measure and its associated degrees of freedom and probability level. Large chi-square values correspond to bad fit and small chi-square values respond to good fit. The degrees of freedom are a standard by which to judge whether chi-square is large or small. The ratio of the chi-square statistic to the degrees of freedom ideally should not exceed 2.0 (Byrne, 1989). The second criterion was the goodness of fit index (GFI), which measures the relative amount of variances and covariances jointly accounted for by the model. This index ranges from 0 to 1.0 . Its value ideally should be .90 or higher. The third criterion was the coefficient of determination for all the observed variables jointly. It also ranges between 0 and 1.0 , with values close to 1.0 representing a good fit. The fourth criterion was the root mean square residual (RMR), which reflects the average discrepancy between the elements in the sample and hypothesized covariance matrices. The RMR also ranges between 0 and 1.0. Its value ideally should be .05 or lower (Byrne, 1989).

In addition, other criteria used to assess model fit were the individual parameter estimates (as measured by the ML method) and the associated $t$-values. These last two criteria help the researcher isolate parameters contributing to the overall misfit of a hypothesized model. An individual parameter estimate reflects the loading of its corresponding indicator on a latent factor or dimension. The $t$-value associated with the parameter estimate indicates the statistical significance of the parameter. As a rule of thumb, $t$-values greater than 2.00 indicate statistically significant parameters.

The unidimensionality of the strategic model as represented in Figure 1 was assessed using the criteria discussed above. LISREL provides all these statistics in the output. It was found that the $t$-values of all 10 individual parameter estimates were greater than 2.0 and, thus, significant. However, the coefficient of determination (.75) and RMR (.07) were not in their respective ideal ranges. The ratio of the chi-square statistic to the degrees of freedom was 3.19, higher than the ideal maximum of 2.0 .

The informational model shown in Figure 1 was assessed similarly. All but one of the nine $t$-values were significant. Following the "restricted analysis" methodology described earlier, the model was respecified and reestimated after dropping the insignificant parameter (corresponding to Item \#23). Upon reestimation, all eight parameters were found to be significant. After reestimation, however, the coefficient of determination was 82 , not in the ideal range. Also, the ratio of the chi-square statistic to the degrees of freedom was 3.82 , higher than the desirable maximum. The RMR was the only overall statistic whose value (.05) was within its ideal range. 
Table 6: Full correlation matrix for the 33 indicators (items).

\begin{tabular}{lrrrrrrrrrrr}
\hline & \multicolumn{1}{c}{$\mathrm{I} 1$} & $\mathrm{I} 2$ & $\mathrm{I} 3$ & $\mathrm{I} 4$ & $\mathrm{I} 5$ & $\mathrm{I} 6$ & $\mathrm{I} 7$ & $\mathrm{I} 8$ & $\mathrm{I} 9$ & $\mathrm{I} 10$ & $\mathrm{I} 11$ \\
\hline $\mathrm{I} 1$ & 1.00 & & & & & & & & & & \\
$\mathrm{I} 2$ & .28 & 1.00 & & & & & & & & & \\
$\mathrm{I} 3$ & .16 & .15 & 1.00 & & & & & & & & \\
$\mathrm{I} 4$ & .02 & .09 & .26 & 1.00 & & & & & & & \\
$\mathrm{I} 5$ & .04 & .04 & .04 & .22 & 1.00 & & & & & & \\
$\mathrm{I} 6$ & .08 & .03 & .23 & .26 & .37 & 1.00 & & & & & \\
$\mathrm{I} 7$ & .11 & .08 & .01 & .08 & .02 & -.10 & 1.00 & & & & \\
$\mathrm{I} 8$ & .05 & .08 & .13 & .00 & -.05 & -.07 & .27 & 1.00 & & & \\
$\mathrm{I} 9$ & .16 & .21 & .24 & .15 & .11 & .08 & .23 & .56 & 1.00 & & \\
$\mathrm{I} 10$ & .07 & .15 & .13 & .11 & .11 & .01 & .33 & .51 & .40 & 1.00 & \\
$\mathrm{I} 11$ & .05 & .21 & .19 & .24 & .22 & .18 & .00 & -.06 & .00 & -.03 & 1.00 \\
$\mathrm{I} 12$ & .18 & .20 & .18 & .22 & .05 & .01 & .18 & .19 & .36 & .29 & .06 \\
$\mathrm{I} 13$ & .04 & .22 & .12 & .15 & .04 & .01 & .17 & .26 & .19 & .38 & .09 \\
$\mathrm{I} 14$ & .06 & .12 & .25 & .19 & .04 & .04 & .15 & .44 & .42 & .31 & .26 \\
$\mathrm{I} 15$ & .07 & .15 & .17 & .20 & .30 & .20 & -.09 & .17 & .22 & .14 & .24 \\
$\mathrm{I} 16$ & .00 & .13 & .07 & .15 & .21 & .03 & .22 & .23 & .25 & .26 & .09 \\
$\mathrm{I} 17$ & .00 & .15 & .01 & .19 & .09 & .00 & .25 & .14 & .09 & .32 & .02 \\
$\mathrm{I} 18$ & .06 & .18 & .09 & .21 & .14 & .01 & .26 & .23 & .21 & .30 & .07 \\
$\mathrm{I} 19$ & .13 & .13 & .06 & .23 & .17 & .06 & .15 & .19 & .15 & .34 & .10 \\
$\mathrm{I} 20$ & .05 & .17 & .13 & .25 & .34 & .17 & .07 & .04 & .10 & .24 & .32 \\
$\mathrm{I} 21$ & .12 & .14 & .07 & .24 & .10 & .04 & .17 & .17 & .20 & .36 & .14 \\
$\mathrm{I} 22$ & .01 & .26 & .09 & .13 & .07 & -.10 & .31 & .20 & .10 & .30 & .12 \\
$\mathrm{I} 23$ & .04 & .23 & .07 & .18 & .14 & .09 & .03 & .26 & .34 & .31 & .16 \\
$\mathrm{I} 24$ & .00 & .15 & .15 & .14 & .12 & -.01 & .19 & .48 & .46 & .36 & .06 \\
$\mathrm{I} 25$ & .06 & .17 & .26 & .14 & .12 & .03 & .06 & .40 & .40 & .24 & .15 \\
$\mathrm{I} 26$ & .00 & .24 & .15 & .11 & .20 & -.04 & .13 & .48 & .40 & .34 & .11 \\
$\mathrm{I} 27$ & .02 & .07 & .12 & .12 & .13 & -.06 & .31 & .20 & .11 & .36 & .08 \\
$\mathrm{I} 28$ & .04 & .04 & .05 & .16 & .09 & .02 & .27 & .15 & .03 & .27 & .15 \\
$\mathrm{I} 29$ & .01 & .21 & .11 & .18 & .17 & .08 & .20 & .28 & .30 & .36 & .07 \\
$\mathrm{I} 30$ & .06 & .20 & .22 & .11 & .02 & .15 & .11 & .38 & .19 & .35 & .12 \\
$\mathrm{I} 31$ & .08 & .21 & .11 & .12 & .01 & -.05 & .25 & .25 & .20 & .28 & .07 \\
$\mathrm{I} 32$ & .13 & .25 & .27 & .33 & .21 & .14 & .10 & .18 & .29 & .26 & .25 \\
$\mathrm{I} 33$ & .03 & .16 & .16 & .23 & .25 & .16 & .10 & .28 & .30 & .36 & .14 \\
\hline & & & & & & & & & & &
\end{tabular}


Table 6: (continued) Full correlation matrix for the 33 indicators (items).

\begin{tabular}{|c|c|c|c|c|c|c|c|c|c|c|c|}
\hline & I12 & I13 & I14 & I15 & I16 & I17 & I18 & I19 & I20 & I21 & $\mathrm{I} 22$ \\
\hline I12 & 1.00 & & & & & & & & & & \\
\hline I13 & .24 & 1.00 & & & & & & & & & \\
\hline I14 & .24 & .16 & 1.00 & & & & & & & & \\
\hline I15 & .14 & .23 & .27 & 1.00 & & & & & & & \\
\hline I16 & .24 & .27 & .13 & .41 & 1.00 & & & & & & \\
\hline I17 & .29 & .40 & .11 & .11 & .21 & 1.00 & & & & & \\
\hline I18 & .30 & .39 & .20 & .22 & .30 & .48 & 1.00 & & & & \\
\hline I19 & .27 & .45 & .21 & .39 & .29 & .46 & .62 & 1.00 & & & \\
\hline $\mathrm{I} 20$ & .17 & .26 & .11 & .35 & .29 & .19 & .42 & .38 & 1.00 & & \\
\hline I21 & .26 & .48 & .20 & .19 & .24 & .58 & .51 & .56 & .34 & 1.00 & \\
\hline $\mathrm{I} 22$ & .33 & .41 & .31 & .14 & .21 & .43 & .52 & .46 & .25 & .46 & 1.00 \\
\hline I 23 & .15 & .39 & .38 & .19 & .24 & .37 & .40 & .29 & .35 & .36 & .33 \\
\hline I 24 & .22 & .16 & .54 & .17 & .16 & .22 & .26 & .18 & .11 & .22 & .26 \\
\hline I 25 & .25 & .13 & .50 & .33 & .20 & .00 & .09 & .08 & .15 & .07 & .12 \\
\hline I26 & .21 & .20 & .47 & .24 & .24 & .12 & .18 & .17 & .17 & .23 & .29 \\
\hline I27 & .28 & .60 & .22 & .14 & .20 & .39 & .45 & .49 & .24 & .51 & .57 \\
\hline I 28 & .31 & .36 & .12 & .07 & .15 & .28 & .43 & .33 & .27 & .44 & .50 \\
\hline I 29 & .28 & .23 & .20 & .16 & .14 & .34 & .37 & .21 & .24 & .32 & .30 \\
\hline $\mathrm{I} 30$ & .19 & .23 & .21 & .19 & .19 & .01 & .15 & .22 & .20 & .12 & .18 \\
\hline I31 & .15 & .24 & .22 & .05 & .16 & .21 & .23 & .22 & .21 & .29 & .41 \\
\hline I32 & .33 & .35 & .28 & .27 & .26 & .28 & .41 & .37 & .52 & .38 & .35 \\
\hline \multirow[t]{2}{*}{ I33 } & .36 & .29 & .16 & .34 & .26 & .19 & .38 & .43 & .32 & .34 & .31 \\
\hline & I 23 & I 24 & I 25 & I26 & I 27 & I28 & I29 & I30 & I31 & I32 & I33 \\
\hline $\mathrm{I} 23$ & 1.00 & & & & & & & & & & \\
\hline $\mathrm{I} 24$ & .35 & 1.00 & & & & & & & & & \\
\hline 125 & .26 & .51 & 1.00 & & & & & & & & \\
\hline I 26 & .31 & .60 & .67 & 1.00 & & & & & & & \\
\hline I27 & .26 & .23 & .12 & .16 & 1.00 & & & & & & \\
\hline I 28 & .18 & .10 & .00 & .08 & .59 & 1.00 & & & & & \\
\hline 129 & .43 & .43 & .22 & .31 & .26 & .32 & 1.00 & & & & \\
\hline I30 & .28 & .27 & .34 & .28 & .26 & .29 & .29 & 1.00 & & & \\
\hline I31 & .31 & .33 & .19 & .35 & .39 & .30 & .39 & .29 & 1.00 & & \\
\hline I32 & .44 & .22 & .34 & .22 & .38 & .34 & .35 & .29 & .24 & 1.00 & \\
\hline I33 & .22 & .24 & .20 & .26 & .40 & .37 & .28 & .36 & .35 & .32 & 1.00 \\
\hline
\end{tabular}


Table 7: Pairwise assessment of discriminant validity for the initial strategic, informational, and transactional dimensions.

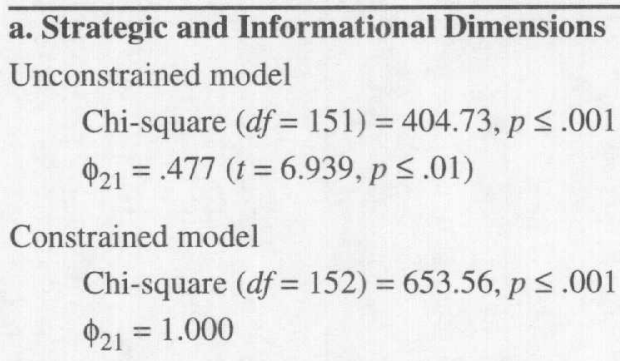

Difference in Chi-square $(d f=1)=248.83, p \leq .001$

b. Strategic and Transactional Dimensions

Unconstrained model

Chi-square $(d f=251)=545.05, p \leq 0.001$

$\phi_{21}=.628(t=10.163, p \leq .01)$

Constrained model

Chi-square $(d f=252)=596.90, p \leq .001$

$\phi_{21}=1.000$

Difference in Chi-square $(d f=1)=51.85, p \leq .001$

c. Informational and Transactional Dimensions

Unconstrained model

Chi-square $(d f=229)=464.88, p \leq .001$

$\phi_{21}=.696(t=12.879, p \leq .01)$

Constrained model

Chi-square $(d f=230)=536.02, p \leq .001$

$\phi_{21}=1.000$

Difference in Chi-square $(d f=1)=71.14, p \leq .001$

The analysis of the transactional model depicted in Figure 1 yielded significant $t$-values for 13 of the 14 parameters. The insignificant parameter (corresponding to Item \#1) was dropped and the model respecified and reestimated. Upon reestimation, all 13 parameters were found to be significant. However, the coefficient of determination (.57) and the RMR (.07) were not in their respective ideal ranges.

These results do not provide strong evidence of the unidimensionality (convergent validity) for any of the three dimensions. Thus, although the informational, strategic, and transactional dimensions had earlier been shown to be distinctly different from each other, they are not unidimensional in themselves. The implication of these results was quite clear: each of the three so-called dimensions were themselves multidimensional and could in turn be "broken down" into several 
subdimensions. This implication was by no means grounds for the refutation and abandonment of the framework. On the contrary, it provided a partial validation of the existence of three dimensions whose structures deserved further examination. Therefore, the identification of these subdimensions and their indicators (items) became the focus of the remainder of the study. The new objective was to uncover the true structures of these three "dimensions." As will be shown in the next section, this was achieved by means of empirical procedures that led to the refinement of the framework and, at the same time, the validation of its essence.

\section{Refinement of the Initial Models}

The various subdimensions and their respective indicators were uncovered using separate but identical iterative analyses for the strategic, informational, and transactional dimensions. In order to ensure that the revised models that resulted from these analyses were robust, projects with known budget amounts $(n=117)$ were divided into two data sets. The first data set consisted of projects with budgets less than or equal to $\$ 500,000(n=63)$. The second data set consisted of projects with budgets between $\$ 500,000$ and $\$ 10,000,000(n=50)$. Four projects with budgets between $\$ 10,000,000$ and $\$ 100,000,000$ were left out of this classification as their large budgets made them clear outliers. The first data set was used for the iterative analyses that culminated with the refinement of each of the three dimensions. The second data set was subsequently used to validate the three refined models.

\section{Iterative Analyses}

These analyses were conducted using the first data set (budgets $\leq \$ 500,000$; $n=63$ ). Each set of iterative analyses began with the assumption that the dimension in question actually consisted of two subdimensions (since it had to be more than one). In this revised LISREL model, all parameters corresponding to one of the subdimensions was set free, to be estimated by LISREL. All parameters corresponding to the other subdimension were fixed to zero values. In other words, although two subdimensions were hypothesized, every indicator was forced under one of them, leaving no indicators under the other. With these specifications as the starting point, the model was estimated and the LISREL output obtained. For each fixed parameter in a model, LISREL provides a modification index (MI). The MI represents the expected drop in chi-square (lower chi-square values imply better models) if that particular parameter were set free. The higher the MI, the greater is the expected drop in chi-square. LISREL automatically prints out the fixed parameter having the highest MI. Using this information from the output, the item corresponding to the parameter with the highest MI was forced over from the first to the second subdimension (the fixed and free parameters corresponding to this item were interchanged). The resulting new model was reestimated with no other changes. This process was repeated in several iterations, and these iterations resulted in several items being moved from the first to the second subdimension. Inevitably, all statistics improved incrementally after each iteration. Any items with MI values greater than 5.0 that repeatedly shifted back and forth between subdimensions in successive iterations were dropped from the model altogether, as they represented poor indicators (Jöreskog \& Sörbom, 1986). Dropping such items always resulted in further 
improvement of overall statistics. The iterative process was discontinued when overall statistics did not improve any more. Thus, for a given number of subdimensions, the last iteration always yielded the best individual parameter statistics (i.e., high parameter estimates and $t$-values, and low standard errors and MIs) as well as best overall statistics (i.e., highest GFI and coefficient of determination, and lowest chi-square and RMR).

Additional subdimensions were introduced one at a time and the iterative process repeated, to compare the two-subdimension model with a three-subdimensional model, a four-subdimensional model, etc. In each of the three sets of analyses, it was seen that the best results corresponded to a particular number of subdimensions and that the statistics deteriorated upon the introduction of additional subdimensions beyond this number. In this methodical manner, the "ideal" structures for the informational, strategic, and transactional dimensions were uncovered. Coincidentally, all three ideal structures were found to consist of three subdimensions.

Although the process described above was empirical in nature, the important consideration was that the starting points for the analyses were derived from theory. The statistics at the culmination of these analyses also made substantive sense because the resulting subdimensions were easily interpreted by examining the indicators that constituted them. For instance, the strategic dimension consisted of three subdimensions that were easily interpreted as competitive advantage, alignment, and customer relations. Likewise, the informational dimension consisted of information access, information quality, and information flexibility, and the transactional dimension consisted of communications efficiency, systems development efficiency, and business efficiency.

The relevant statistics resulting from the "best" iterations (using data from projects with budgets less than or equal to $\$ 500,000$ ) for the strategic, informational, and transactional dimensions are summarized in Tables 8,9 , and 10, respectively. These tables demonstrate excellent values for the individual parameter estimates and for most of the overall statistics.

In addition to all these analyses, the validity of the initial three-way assignment of the 33 indicators (items) was examined by conducting a principal components analysis followed by a varimax rotation. Nine factors emerged. Although these factors are not listed here, a brief summary follow's. Indicators that loaded on Factor 1 were virtually identical to our informational category. Indicators loading on Factor 2 together with the lone indicator in Factor 8 corresponded to our strategic category. Indicators loading on Factors 3, 4, 5, 6, 7, and 9 represented a split of our transactional category. It was interesting that this split resembled the transactional category subdimensions uncovered by means of the iterative analyses mentioned above. Three indicators, one for each assigned category, did nut load clearly on any of the nine factors.

\section{Validation of Refined Models}

The refined strategic, informational, and transactional models were tested for robustness using the second data set, consisting of projects with budgets between $\$ 500,000$ and $\$ 10,000,000(n=50)$. Despite the fact that the sample size of this test 
Table 8: The revised (multidimensional) strategic model derived from iterative analyses on projects with budgets $\leq \$ 500,000(n=63)$.

\begin{tabular}{|c|c|c|c|}
\hline \multicolumn{2}{|c|}{$\begin{array}{l}\text { Chi-square }(d f=17)=19.80, p \leq .285 \\
\text { Goodness of fit index }(\mathrm{GFI})=.930\end{array}$} & \multicolumn{2}{|c|}{$\begin{array}{l}\text { Coefficient of determination }=.980 \\
\text { Root mean square residual }(\mathrm{RMR})=.048 \\
\text { Subdimensions }\end{array}$} \\
\hline $\begin{array}{l}\text { Item Number } \\
\text { from Table } 2\end{array}$ & $\begin{array}{l}\text { Competitive } \\
\text { Advantage }\end{array}$ & Alignment & $\begin{array}{l}\text { Customer } \\
\text { Relations }\end{array}$ \\
\hline \multicolumn{4}{|c|}{ Maximum Likelihood Estimates } \\
\hline I8 & .810 & .000 & .000 \\
\hline I9 & .652 & .000 & .000 \\
\hline $\mathrm{I} 10$ & .000 & .629 & .000 \\
\hline $\mathrm{I} 12$ & .000 & .719 & .000 \\
\hline $\mathrm{I} 33$ & .000 & .692 & .000 \\
\hline $\mathrm{I} 24$ & .000 & .000 & .735 \\
\hline $\mathrm{I} 25$ & .000 & .000 & .817 \\
\hline $\mathrm{I} 26$ & .000 & .000 & .932 \\
\hline \multicolumn{4}{|l|}{$t$-Values } \\
\hline I8 & 6.198 & 0.000 & 0.000 \\
\hline I9 & 5.040 & 0.000 & 0.000 \\
\hline $\mathrm{I} 10$ & 0.000 & 4.824 & 0.000 \\
\hline $\mathrm{I} 12$ & 0.000 & 5.630 & 0.000 \\
\hline $\mathrm{I} 33$ & 0.000 & 5.394 & 0.000 \\
\hline $\mathrm{I} 24$ & 0.000 & 0.000 & 6.480 \\
\hline $\mathrm{I} 25$ & 0.000 & 0.000 & 7.472 \\
\hline I26 & 0.000 & 0.000 & 9.069 \\
\hline \multicolumn{4}{|c|}{ Modification Indices } \\
\hline I8 & 0.000 & 0.432 & 0.432 \\
\hline I9 & 0.000 & 0.432 & 0.432 \\
\hline $\mathrm{I} 10$ & 1.579 & 0.000 & 0.001 \\
\hline $\mathrm{I} 12$ & 0.266 & 0.000 & 0.060 \\
\hline $\mathrm{I} 33$ & 0.513 & 0.000 & 0.049 \\
\hline $\mathrm{I} 24$ & 3.630 & 0.869 & 0.000 \\
\hline $\mathrm{I} 25$ & 0.404 & 0.117 & 0.000 \\
\hline $\mathrm{I} 26$ & 4.478 & 1.063 & 0.000 \\
\hline
\end{tabular}


Table 8: (continued) The revised (multidimensional) strategic model derived from iterative analyses on projects with budgets $\leq \$ 500,000(n=63)$.

\begin{tabular}{lccc}
\hline & \multicolumn{3}{c}{ Subdimensions } \\
\cline { 2 - 4 } $\begin{array}{l}\text { Item Number } \\
\text { from Table 2 }\end{array}$ & $\begin{array}{c}\text { Competitive } \\
\text { Advantage }\end{array}$ & Alignment & $\begin{array}{c}\text { Customer } \\
\text { Relations }\end{array}$ \\
\hline Standard Errors & & & \\
I8 & .131 & .000 & .000 \\
I9 & .129 & .000 & .000 \\
I10 & .000 & .130 & .000 \\
I12 & .000 & .128 & .000 \\
I33 & .000 & .128 & .000 \\
I24 & .000 & .000 & .113 \\
I25 & .000 & .000 & .109 \\
I26 & .000 & .000 & .103 \\
\hline
\end{tabular}

Note: Items 7 and 14 were dropped.

data set was relatively small, the validation analyses ylelded very good results, confirming the validity of the dimensions and subdimensions in the three models. Table 11 summarizes the overall statistics from these validation analyses. The indicators that constitute each subdimension in the final model are listed in Table 12.

\section{IMPLICATIONS AND LIMITATIONS}

This research has offered an instrument for measuring the organizational benefits of information systems projects. The items in this instrument have been shown to be classified into three dimensions of organizational benefits: strategic. informational, and transactional. Each dimension, in turn, consists of three subdimensions. This instrument has important implications for researchers and practitioners, which will be discussed following a brief description of its dimensional components.

Strategic benefits are broken down into competitive advantage, alignment, and customer relations. Competitive advantage benefits help the organization introduce radical changes to its business processes and thereby create competitive advantage for itself or reduce the existing advantage of its competitors. Alignment benefits directly support organizational goals, help the organization create linkages with other organizations (such as competitors, suppliers and customers), or enable it to orient itself and respond faster to environmental changes. Customer relations benefits directly enhance the customers' perception of the organizational image, usually through improved products or better service.

Informational benefits are broken down into information access, information quality, and information flexibility. Information access benefits provide organizational decision makers with faster and/or easier access to internal and external information. Information quality benefits make the available information more useful, accurate, and reliable. Information flexibility benefits allow decision makers to easily manipulate the content and format of retrieved information. 
Table 9: The revised (multidimensional) informational model derived from iterative analyses on projects with budgets $\leq \$ 500,000(n=63)$.

\begin{tabular}{|c|c|c|c|}
\hline \multirow{2}{*}{\multicolumn{2}{|c|}{$\begin{array}{l}\text { Chi-square }(d f=11)=12.30, p \leq .342 \\
\text { Goodness of fit index }(\mathrm{GFI})=.946\end{array}$}} & \multirow{2}{*}{\multicolumn{2}{|c|}{$\begin{array}{l}\text { Coefficient of determination }=.928 \\
\text { Root mean square residual }(\mathrm{RMR})=.038\end{array}$}} \\
\hline & & & \\
\hline \multirow[b]{2}{*}{$\begin{array}{l}\text { Item Number } \\
\text { from Table } 2\end{array}$} & \multicolumn{3}{|c|}{ Subdimensions } \\
\hline & $\begin{array}{l}\text { Information } \\
\text { Access }\end{array}$ & $\begin{array}{c}\text { Information } \\
\text { Quality }\end{array}$ & $\begin{array}{l}\text { Information } \\
\text { Flexibility }\end{array}$ \\
\hline \multicolumn{4}{|c|}{ Maximum Likelihood Estimates } \\
\hline I17 & .738 & .000 & .000 \\
\hline I21 & .853 & .000 & .000 \\
\hline I13 & .000 & .686 & .000 \\
\hline $\mathrm{I} 22$ & .000 & .775 & .000 \\
\hline $\mathrm{I} 28$ & .000 & .724 & .000 \\
\hline I18 & .000 & .000 & .758 \\
\hline I19 & .000 & .000 & .688 \\
\hline \multicolumn{4}{|l|}{$t$-Values } \\
\hline I17 & 6.357 & 0.000 & 0.000 \\
\hline $\mathrm{I} 21$ & 7.598 & 0.000 & 0.000 \\
\hline I13 & 0.000 & 5.808 & 0.000 \\
\hline $\mathrm{I} 22$ & 0.000 & 6.834 & 0.000 \\
\hline $\mathrm{I} 28$ & 0.000 & 6.236 & 0.000 \\
\hline I18 & 0.000 & 0.000 & 6.148 \\
\hline I19 & 0.000 & 0.000 & 5.557 \\
\hline \multicolumn{4}{|c|}{ Modification Indices } \\
\hline I17 & 0.000 & 0.873 & 0.873 \\
\hline $\mathrm{I} 21$ & 0.000 & 0.873 & 0.873 \\
\hline I13 & 0.846 & 0.000 & 0.690 \\
\hline $\mathrm{I} 22$ & 2.101 & 0.000 & 0.611 \\
\hline $\mathrm{I} 28$ & 5.689 & 0.000 & 2.592 \\
\hline I18 & 1.448 & 1.449 & 0.000 \\
\hline I19 & 1.448 & 1.448 & 0.000 \\
\hline \multicolumn{4}{|c|}{ Standard Errors } \\
\hline I17 & .116 & .000 & .000 \\
\hline $\mathrm{I} 21$ & .112 & .000 & .000 \\
\hline I13 & .000 & .118 & .000 \\
\hline $\mathrm{I} 22$ & .000 & .113 & .000 \\
\hline $\mathrm{I} 28$ & .000 & .116 & .000 \\
\hline I18 & .000 & .000 & .123 \\
\hline I19 & .000 & .000 & .124 \\
\hline
\end{tabular}

Note: Item 27 was dropped. 
Table 10: The revised (multidimensional) transactional model derived from iterative analyses on projects with budgets $\leq \$ 500,000(n=63)$.

\begin{tabular}{|c|c|c|c|}
\hline \multirow{2}{*}{\multicolumn{2}{|c|}{$\begin{array}{l}\text { Chi-square }(d f=32)=35.71, p \leq .298 \\
\text { Goodness of fit index }(\mathrm{GFI})=.897\end{array}$}} & \multicolumn{2}{|c|}{ Coefficient of determination $=.857$} \\
\hline & & Root mean square resid & $(R M R)=.086$ \\
\hline \multirow[b]{2}{*}{$\begin{array}{l}\text { Item Number } \\
\text { from Table } 2\end{array}$} & \multicolumn{3}{|c|}{ Subdimensions } \\
\hline & $\begin{array}{l}\text { Communications } \\
\text { Efficiency }\end{array}$ & $\begin{array}{l}\text { Systems Development } \\
\text { Efficiency }\end{array}$ & $\begin{array}{l}\text { Business } \\
\text { Efficiency }\end{array}$ \\
\hline \multicolumn{4}{|c|}{ Maximum Likelihood Estimates } \\
\hline I3 & .556 & .000 & .000 \\
\hline I4 & .526 & .000 & .000 \\
\hline I5 & .000 & .388 & .000 \\
\hline I15 & .000 & .661 & .000 \\
\hline $\mathrm{I} 16$ & .000 & .783 & .000 \\
\hline $\mathrm{I} 20$ & .000 & .491 & .000 \\
\hline $\mathrm{I} 2$ & .000 & .000 & .308 \\
\hline $\mathrm{I} 29$ & .000 & .000 & .632 \\
\hline $\mathrm{I} 30$ & .000 & .000 & .359 \\
\hline I31 & .000 & .000 & .567 \\
\hline \multicolumn{4}{|l|}{$t$-Values } \\
\hline I3 & 3.168 & 0.000 & 0.000 \\
\hline I4 & 3.077 & 0.000 & 0.000 \\
\hline I5 & 0.000 & 2.748 & 0.000 \\
\hline I15 & 0.000 & 4.847 & 0.000 \\
\hline I16 & 0.000 & 5.714 & 0.000 \\
\hline $\mathrm{I} 20$ & 0.000 & 3.545 & 0.000 \\
\hline I2 & 0.000 & 0.000 & 1.991 \\
\hline I29 & 0.000 & 0.000 & 4.051 \\
\hline $\mathrm{I} 30$ & 0.000 & 0.000 & 2.332 \\
\hline I31 & 0.000 & 0.000 & 3.696 \\
\hline \multicolumn{4}{|l|}{ Modification Indices } \\
\hline I3 & 0.000 & 1.072 & 1.072 \\
\hline I4 & 0.000 & 1.072 & 1.072 \\
\hline I5 & 0.001 & 0.000 & 0.271 \\
\hline I15 & 0.953 & 0.000 & 3.300 \\
\hline I16 & 0.027 & 0.000 & 0.013 \\
\hline $\mathrm{I} 20$ & 2.203 & 0.000 & 4.546 \\
\hline I2 & 0.080 & 0.381 & 0.000 \\
\hline I29 & 0.197 & 2.225 & 0.000 \\
\hline 130 & 0.719 & 1.268 & 0.000 \\
\hline I31 & 0.164 & 3.849 & 0.000 \\
\hline
\end{tabular}

Reproduced with permission of the copyright owner. Further reproduction prohibited without permission. 
Table 10: (continued) The revised (multidimensional) transactional model derived from iterative analyses on projects with budgets $\leq \$ 500,000(n=63)$.

\begin{tabular}{lccc}
\hline \multirow{2}{*}{$\begin{array}{l}\text { Item Number } \\
\text { from Table 2 }\end{array}$} & $\begin{array}{c}\text { Subdimensions } \\
\text { Communications } \\
\text { Efficiency }\end{array}$ & $\begin{array}{c}\text { Systems Development } \\
\text { Efficiency }\end{array}$ & $\begin{array}{c}\text { Business } \\
\text { Efficiency }\end{array}$ \\
\hline Standard Errors & & & \\
I3 & .175 & .000 & .000 \\
I4 & .171 & .000 & .000 \\
I5 & .000 & .141 & .000 \\
I15 & .000 & .136 & .000 \\
I16 & .000 & .137 & .000 \\
I20 & .000 & .138 & .000 \\
I2 & .000 & .000 & .155 \\
I29 & .000 & .000 & .156 \\
I30 & .000 & .000 & .154 \\
I31 & .000 & .000 & .154 \\
\hline
\end{tabular}

Note: Items 6,11 , and 32 were dropped.

Finally, transactional benefits are also of three types: communications efficiency, systems development efficiency, and business efficiency. Communications efficiency benefits reduce the costs of organizational communication (e.g., travel costs). Systems development efficiency benefits make it possible for systems development and maintenance activities to be faster and cheaper. Lastly, business efficiency benefits improve the overall efficiency of employees, business processes, and financial resources. The implications of this instrument for both researchers and practitioners follow.

\section{Implications for Research}

As our study has proposed specific refinements to the tested framework. an obvious research implication is the need to test these proposed refinements by a replication of this study using different data sources. A replication would either raise new issues or generate confidence in our instrument and both would be desirable outcomes.

The proposed instrument has major implications for the dependent side of potential relationships explored in research questions. Researchers often hypothesize and test the impacts of various individual, IS, and organizational variables on IS effectiveness and/or organizational effectiveness. In such studies, this instrument would help in the operationalization of organizational benefits of IS when used as an appropriate dependent construct.

This instrument can also be used by researchers as an aid in generating research designs. For instance, groups of similar projects based on their anticipated or realized benefits may be identified by applying it to proposed projects. This would be useful in isolating certain types of IS projects for further exploration and study. 
Table 11: Validation of the revised strategic, informational, and transactional models using second set of data (project budgets $\$ 500,000-\$ 10,000,000$; $n=50)$.

\begin{tabular}{lccc}
\hline & Strategic & Informational & Transactional \\
\hline Chi-square & 18.19 & 16.35 & 22.17 \\
& $(d f=17$, & $(d f=11$, & $(d f=32$, \\
& $p \leq .377)$ & $p \leq .129)$ & $p \leq .903)$ \\
Coefficient of determination & .892 & .928 & .942 \\
Goodness of fit index (GFI) & .922 & .908 & .924 \\
$\begin{array}{l}\text { Root mean square residual } \\
\text { (RMR) }\end{array}$ & .076 & .061 & .067 \\
\hline
\end{tabular}

The results of this study also imply that any instrument applied to measure IS success should be tailored to the project being assessed. Although this does not follow directly from our study, the fact that the instrument identifies various dimensions of the benefits of IS projects suggests that the assessment of the success of a specific IS project can be meaningful only if the measuring instrument is tailored to compare the anticipated benefits of the project with its realized benefits. However, it should be noted that the use of this instrument to compare anticipated and realized benefits of any IS project is appropriate only if the focus is on success at the organizational level or "locus of value." At the level of the individual IS professional, the definition of success would necessarily be somewhat different and, hence, this instrument would be unsuitable for the measurement of anticipated or realized benefits from that other perspective.

\section{Implications for Practice}

This instrument provides systems analysts and other participants in the benefits estimation process with a checklist of anticipated benefits. It is a useful tool in recognizing and understanding the potential benefits of IS projects, and should serve as an excellent starting point for the analysis of the benefits of any proposed project. It should also help proposers of IS projects to increase their chances of being granted approvals for their projects by focusing on issues that are of pressing concern for senior management.

For senior management and steering committees, the instrument serves as an evaluation tool for assessing the performance of the IS group. They can use it to compare the anticipated benefits of a proposed IS project with its realized benefits after implementation, to assess whether the project met its goals and, hence, whether the IS group was able to meet its commitments. In fact, some subdimensions of this instrument are very similar to the "IS function performance dimensions" identified in a research study by Saunders and Jones (1992). Thus, competitive advantage, alignment, information quality, systems development efficiency, and business efficiency are equivalent, respectively, to the following dimensions from the Saunders and Jones study: IS impact on strategic direction, integration of IS and corporate planning, quality of information outputs, adequacy of system development practice, and IS contribution to organization's financial performance. 
Table 12: Organizational benefits of IS: The final dimensions and items.

The proposed project will ..

\section{Competitive Advantage}

\section{Strategic Benefits}

Enhance competitiveness or create strategic advantage.

Enable the organization to catch up with competitors.

\section{Alignment}

Align well with stated organizational goals.

Help establish useful linkages with other organizations.

Enable the organization to respond more quickly to change.

\section{Customer Relations}

Improve customer relations.

Provide new products or services to customers.

Provide better products or services to customers.

\section{Informational Benefits}

\section{Information Access}

Enable faster retrieval or delivery of information or reports.

Enable easier access to information.

\section{Information Quality}

Improve management information for strategic planning.

Improve the accuracy or reliability of information.

Improve information for operational control.

\section{Information Flexibility}

Present information in a more concise manner or better format.

Increase the flexibility of information requests.

\section{Communications Efficiency}

\section{Transactional Benefits}

Save money by reducing travel costs.

Save money by reducing communication costs.

\section{Systems Development Efficiency}

Save money by reducing system modification or enhancement costs.

Allow other applications to be developed faster.

Allow previously infeasible applications to be implemented.

Provide the ability to perform maintenance faster.

\section{Business Efficiency}

Save money by avoiding the need to increase the work force.

Speed up transactions or shorten product cycles.

Increase return on financial assets.

Enhance employee productivity or business efficiency. 
These similarities further contribute to the validity of the notion that this instrument can indeed serve as an evaluation tool for the performance assessment of IS groups.

\section{Limitations}

The major limitations of this study stem from the manner in which data were collected. First, the sample of respondents were all IS professionals. It was their perceptions that this study captured and analyzed. Had the respondents been functional area managers or senior management, these perceptions, and hence the data collected, might have been different. In particular, users tend to have a better appreciation of strategic kinds of benefits as compared to IS professionals, and IS professionals tend to be more sensitized towards system-oriented benefits. It should be emphasized here that a complete assessment of the organizational benefits of any IS project should entail capturing the perspectives of individual users, their managers, systems developers, project champions and, in general, as many constituencies as possible. Thus, this instrument should not be used in isolation, but rather in conjunction with other measurement tools emphasizing different constituencies and gathering data at various levels.

Moreover, respondents were asked to report the anticipated benefits of projects they had analyzed recently, as they best recalled them. Any inability on their part to completely and accurately recall these recent past events may have introduced some distortion in the data. In addition, the data captured reflected the anticipated benefits of projects at the time they were proposed, not the realized benefits after implementation, which could well have been different. Finally, approved projects were included in the data analysis, but rejected projects were not. All these factors may have contributed to the unintended imposition of various filters, distortions, and biases on the data collected. In addition, the response rate of $22 \%$ was relatively low, although this is typical of surveys with lengthy questionnaires. Despite the encouraging results of the nonresponse bias analysis, researchers should exercise caution and judgment in extrapolating the results of the study from the responding sample to the broader population. In summary, future replications of this study with different data collection methodologies and samples are needed to address these issues. [Received: January 18, 1996. Accepted: October 29, 1997.]

\section{REFERENCES}

Anderson, J. C., \& Gerbing, D. W. (1988). Structural equation modeling in practice: A review and recommended two-step approach. Psychological Bulletin, $103(3), 411-423$.

Anonymous. (1990), Evaluating technology's payback. IBM Directions, 4(3), 29-31.

Bacon, C. J. (1992). The use of decision criteria in selecting information systems/ technology investments. MIS Quarterly, 16(3), 335-354. 
Bagozzi, R. P., \& Phillips, L. W. (1982). Representing and testing organizational theories: A holistic construal. Administrative Science Quarterly, 27, 459489.

Bailey, J. E., \& Pearson, S. W. (1983). Development of a tool for measuring and analyzing computer user satisfaction. Management Science, 29(5), 530-545.

Bakos, Y., \& Treacy, M. E. (1986). Information technology and corporate strategy: A research perspective. MIS Quarterly, 10(2), 107-119.

Barti, H., \& Huff, S. (1985). Change, attitude to change, and decision support system success, Information \& Management, 9(5), 261-268.

Byrne, B. M. (1989). A primer of LISREL: Basic applications and programming for confirmatory factor analytic models. New York: Springer-Verlag.

Cameron, K. S. (1986). Effectiveness as paradox: Consensus and conflict in conceptions of organizational effectiveness. Management Science, 32(5), 539553.

Cameron, K. S., \& Whetten, D. A. (1983). Organizational effectiveness: A comparison of multiple models. New York: Academic Press.

Campbell, D. T., \& Fiske, D. W. (1959). Convergent and discriminant validation by the multitrait-multimethod matrix. Psychological Bulletin, 56, 81-105.

Cash, J. I., \& Konsynski, B. R. (1985). IS redraws competitive boundaries. Harvard Business Review, 63(2), 134-142.

Cash, J. I., McFarlan, F. W., McKinney, J. L., \& Applegate, L. M. (1992). Corporate information systems management: Text and cases. Homewood, IL: Irwin.

Clemons, E. K. (1991). Evaluation of strategic investment in information technology. Communications of the ACM, 34(1), 22-36.

Cohen, J. (1960). A coefficient of agreement for nominal scales. Educational and Psychological Measurement, 20, 37-46.

Cohen, J. (1968). Weighted kappa: Nominal scale agreement with provision for scaled disagreement or partial credit. Psychological Bulletin, 70, 213-220.

DeLone, W. H., \& McLean, E. R. (1992). Information systems success: The quest for the dependent variable. Information Systems Research, 3(1), 60-95.

Diromualdo, A. P. (1990, December). Toward asset-based IT. CIO Magazine, 18-19.

Doll, W. J., \& Torkzadeh, G. (1988). The measurement of end-user computing satisfaction. MIS Quarterly, 12(2), 259-274.

Dos Santos, B. L. (1991). Justifying investments in new information technologies. Journal of Management Information Systems, 7(4), 71-90.

Farbey, B., Land, F. F., \& Targett, D. (1995). A taxonomy of information systems applications: The benefits' evaluation ladder. European Journal of Information Systems, 4(1), 41-50.

Feeny, D. F., Edwards, B. R., \& Simpson, K. M. (1992). Understanding the CEO/ CIO relationship. MIS Quarterly, 16(4), 435-448. 
Gorry, G. A., \& Scott Morton, M. S. (1971). A framework for management information systems. Sloan Management Review, 13i1), 55-70.

Hall, R. H. (1996). Organizations: Structures, processes, and outcomes (6th ed.). Englewood Cliffs, N.J.: Prentice Hall.

Harris, S. E., \& Katz, J. L. (1991). Organizational performance and information technology investment intensity in the insurance industry. Organi-ational Science, 2(3), 263-295.

Ives, B., \& Learmonth, G. (1984). The information system as a competitive weapon. Communications of the ACM, 27(12), 1193-1201.

Ives, B., Olson, M. H., \& Baroudi, J. J. (1983). The measurement of user information satisfaction. Communications of the ACM, 26(10), 785-793.

Janulaitis, V. M. (1984). Are the risks worth taking? Computerworld, 18(33), 13-22.

Jenkins, A. M., \& Ricketts, J. A. (1979, November). Development of an instrument to measure user satisfaction with management information systems. Report from the School of Business at Indiana University, Bloomington, IN.

Jöreskog, K. G. (1971). Statistical analysis of congeneric tests. Psychometrika, 36, 109-133.

Jöreskog, K. G., \& Sörbom, D. (1986). LISREL VI: Analysis of linear structural relationships by maximum likelihood, instrumental variables, and least squares methods (4th ed.). Mooresville, IN: Scientific Software.

Kauffman, R. J., \& Weill, P. (1989). An evaluative framework for research on the performance effects of information technology investment. Proceedings of the Tenth International Conference on Information Systems, Boston, MA.

Kim, K. K. (1989). User satisfaction: A synthesis of three different perspectives. Journal of Information Systems, Fall, 1-12.

King, J. L., \& Schrems, E. L. (1978). Cost-benefit analysis in information systems development and operation. Computing Surveys. 10(1), 19-34.

Kirs, P. J., Sanders, G. L., Cerveny, R. P., \& Robey, D. (1989). An experimental validation of the Gorry and Scott Morton Framework. MIS Quarterly: 13(2), 183-197.

Klein, K. J., Dansereau, F., \& Hall, R. J. (1994). Level issues in theory development, data collection, and analysis. Academy of Management Review. 19(2), 195-229.

Lay, P. M.W. (1985). Beware of the cost/benefit model for IS project evaluation. Journal of Systems Management, 36(6), 30-35.

Loveman, G. (1988). An assessment of the productivity impact of information technologies. Working Paper 88-054, Massachusetts Institute of Technology Sloan School of Management, Cambridge, MA.

Loveman, G. (1991, November 25). Cash drain, no gain. Computerworld, 69-72.

Lucas, H. C., Jr. (1975). Performance and the use of an information system. Management Science, 21(8), 908-919. 
Maglitta, J. (1993). Executives: Where's the IS payback? Computenworld, 27(42).

McGugan, I. (1987). Competitive advantages vs. tyrannosaurs techie. Computing Canada, 13(9), 18-20.

McLean, E. R., \& Soden, J. V. (1977). Strategic planning for MIS. New York: Wiley \& Sons.

Melone, N. P. (1990). Theoretical assessment of user-satisfaction construct in information systems research. Management Science, 36(1), 76-91.

Orli, R. J., \& Tom, J. C. (1987). If it's worth more than it costs, buy it! Journal of Information Systems Management, 4(3), 85-89.

Ostroff, C. (1993). Comparing correlations based on individual-level and aggregated data. Journal of Applied Psychology, 78(4), 569-582.

Parker, M. M., \& Benson, R. J. (1987). Information economics: An introduction. Datamation, 33(23), 86-96.

Parsons, G. L. (1983). Information technology: A new competitive weapon. Sloan Management Review, 25(1), 3-14.

Porter, M. E., \& Millar, V. E. (1985). How information gives you competitive advantage. Harvard Business Review, 63(4), 149-160.

Powell, P. (1992). Information technology and business strategy: A synthesis of the case for reverse causality. Proceedings of the Thirteenth International Conference on Information Systems, Dallas, TX, 71-80.

Raghunathan, B., \& Raghunathan, T. S. (1994). Adaptation of a planning system success model to information systems planning. Information Systems Research, 5(3), 326-340.

Raymond, L. (1985). Organizational characteristics and MIS success in the context of small business. MIS Quarterly, 9(1), 37-52.

Rivard, E., \& Kaiser, K. (1989). The benefit of quality IS. Datamation, 35(2), 53-58.

Rousseau, D. (1985). Issues of level in organizational research: Multilevel and cross-level perspectives. In L. L. Cummings \& B. M. Staw (Eds.), Research in organizational behavior (Vol. 7). New York: Wiley.

Runge, D., \& Earl, M. (1988). Gaining competitive advantage from telecommunications. In M. Earl (Ed.), Information management: The strategic dimension. Oxford, England: Oxford University Press.

Saunders, C. S., \& Jones, J. W. (1992). Measuring performance of the information systems function. Journal of Management Information Systems, 8(4), 63-82.

Smith, R. D. (1983). Measuring the intangible benefits of computer-based information systems. Journal of Systems Management, 33(9), 22-27.

Srinivasan, A. (1985). Alternative measures of systems effectiveness: Associations and implications. MIS Quarterly, 9(3), 243-253.

Subramanian, A., \& Nilakanta, S. (1994). A blueprint for theory-building in MIS. Information \& Management, 26(1), 13-20. 
Sullivan-Trainor, M. L. (1989). The push for proof of information systems payoff. Computerworld, 23(14), 55-61.

Sullivan-Trainor, M. L. (1990-91). End of IS budgets as we know them? Computerworld, 24(52-53), 15.

Thompson, J. D. (1967). Organizations in action. New York: McGraw-Hill.

Turner, J. (1985). Organizational performance, size, and the use of data processing resources. Working Paper 58, Center for Research in Information Systems, New York University, New York.

Turner, J., \& Lucas, H. C., Jr. (1985). Developing strategic information systems. In W. Guth (Ed.), Handbook of business strategy. Boston, MA: Warren, Gorham and Lamont.

Vaid-Raizada, V. K. (1983). Incorporation of intangibles in computer selection decisions. Journal of Systems Management, 33(11), 30-36.

Venkatraman, N., \& Ramanujam, V. (1987). Planning system success: A conceptualization and an operational model. Management Science, 33(6), 687-705.

Weill, P. (1992). The relationship between investment in information technology and firm performance: A study of the valve manufacturing sector. Information Systems Research, 3(4), 307-333.

Weill, P., \& Olson, M. H. (1989). Managing investment in information technology: Mini case examples and implications. MIS Quarterly, 13(1), 3-17.

Willcocks, L., \& Lester, S. (1991). Information systems investments: Evaluation at the feasibility stage of projects. Technovation, $1 /(5), 283-302$.

Zammuto, R. F. (1984). A comparison of multiple constituency models of organizational effectiveness. Academy of Management Review, 9(4), 606-616.

Rajesh Mirani is an associate professor of information systems at the Merrick School of Business, University of Baltimore. He has a PhD in information systems from the University of Pittsburgh, an MBA from the Indian Institute of Management, Calcutta, and a BTech. (Hons.) in chemical engineering from the Indian Institute of Technology, Kharagpur. His research interests are primarily in the areas of information systems planning and the management of end-user computing. His papers have been published in journals such as Decision Sciences, Journal of Management Information Systems, and MIS Quarterly.

\begin{abstract}
Albert L. Lederer is a professor of management information systems at the C.M. Gatton College of Business and Economics at the University of Kentucky. He has a $\mathrm{PhD}$ in industrial and systems engineering, a masters in computer and information sciences from the Ohio State University, and a BA in psychology from the University of Cincinnati. His research focuses on issues related to information systems planning. He is an associate editor of Decision Sciences.
\end{abstract}

